\title{
SYNTHESIS AND CATEGORY: \\ THE SYNTHESIS OF THE HETEROGENEOUS \\ IN RICOEUR AND KANT
}

This study gathers together texts and notations pertaining to the synthesis of the heterogeneous (a formal description of the plot of a narrative) in Temps et récit. ${ }^{1}$ I am aware of the doubts which have been expressed by a number of francophone critics about the usefulness of this notion. ${ }^{2}$ However, I think it is worthy of investigation, if for no other reason than to compare the notion of a syn. het. with that to which Kant refers under the same title in the first Critique.

First, the references to a syn. het. in TR will be discussed and compared, and any sign of a Kantian origin noted. Next, the function of the syn. het. in Kant will be discussed, with attention to its possible bearing on TR.

The object of the investigation is a better understanding of Ricoeur's relation to Kant. However, sil: the texts in which Ricoeur criticizes or reinterprets Kant directly ( notably in the second chapter of TR III and in the "petite ethique" of Soi-même comme un autre) ${ }^{3}$ are not here taken into consideration, this study can only be regarded as preparation for a study of those texts. However, the theme of the passivity of consciousness (or more particularly, of conscience within consciousness), which is of great importance in Soi, does emerge from the consideration of the syn.het. in Kant, when this is read as if it lay at the foundation of TR. These indications belong, therefore, to a readingstrategy which might be useful in understanding the reworking of the theory of narrative in TR which takes place in Soi. 


\section{1: The synthesis of the heterogeneous in Temps et récit}

The first reference to a syn. het. in argument position in TR occurs.in the "model" of the triple mimesis, in the section on mimesis 2 (TR I, p. 103). In formal terms, the temporal characteristics of the plot make it a syn. het. The plot (l'intrigue) of a narrative is a syn. het. because there are combined in it "deux dimensions temporelles, l'une chronologique, l'autre non-chronologique."

Even though the adjective temporal is not placed in front of the expression, syn. het., until the end of TR II, the context here shows that we should already think of it in that way. The syn. het. is a temporal syn. het. It is the two time-dimensions which are heterogeneous to each other.

Who synthesizes them? The author, the maker of the plot has to try to introduce a sort of necessity in the connection between the episodes leading up to the end. A sequence of sentences is not a narrative, although every narrative must contain a sequence. But connections can be made between widely separated parts of the narrative, not just successive ones. The narrative can anticipate its own end, and flashback to or recall its earlier moments.Further, the plot contains characters who are described as having their own interiorities, with mobile orientations and recollections relative to the action imitated in and by the plot (TR I, p. 59-60). Characters are represented as subject to the same discordance and distension which marks our own temporal experience, as described by St. Augustine in Book XI of the Confessions. But the temporality of the narrative (the contrary of its sequential or chronological aspect), which bends all limited or foreshadowed perspectives toward an end of the story, opposes a model of concordance to this distension, even while including discordant elements within itself (TR I, p. 65, 71-75). The plot is the ratio essendi of the characters. The episodes are conditioned by the end, which retroactively confers necessity upon their arrangement. 
It is along this properly temporal dimension that "new qualities of time" (TR I, p. 105) emerge from the narrative. Narratives can stretch our imaginations to the scale of long temporal action-sequences (represented as such), and show us different ways of belonging to history; in the represented interiority of a fictional character, the temporality of relationships between persons is imaginatively varied. The act of telling stories works to reverse the social entropy of modern life, revivifying our ties to cultures, traditions, families, etc. In a different way, when we have gotten to know certain fictional characters in all their complexity, we become more sensitive to the complexity which may lie hidden beneath everyday encounters. As Ricoeur will continue to hold in Soi, the model of the plot as a syn. het. allows us to combine temporal variability, diversity, and even instability with the relative permanence of the narrative identity of character established in the plot (Soi, p. 167-168).

But in saying this we have already adopted the point of view of the reader. The author performs a syn. het. between two timedimensions, putting together a heterogeneity of elements: circumstances, goals, means, interactions, surprises, success, failure, etc., and thus may be said to configure the work. The configurational act, which the model of mimesis 2 presents as closely related to the syn. het., is described more in terms of the reader. This act takes-together what the author has put together, and from that multiplicity draws "the unity of a temporal totality" (TR I, p. 103).

It is the notion of the configurational act which receives the Kantian mark most explicitly in TR I. The configurational act is compared to reflective judgment as in the third Critique. Ricoeur also recalls how in the first Critique, the categories of pure understanding had to be time-schematized in order to be applied to experience. Ricoeur gives a fair indication of how we should read Kant in order to apply him to this situation: he notes that Kant interested himself mainly with those schemata which facilitated the application of the categories to the "objective constitution of the physical world": 
Le schematisme de la fonction narrative implique des déterminations d'un genre nouveau qui sont précisement celles que l'on vient de designer par dialectique des caractéres episodiques et configurant de la mise en intrigue (TR I, p. 106)

The schematization of this dialectic is not only temporal but historical, in so far as narrative has become a condition of temporal experience, to use the expression of the "general thesis" of TR (TR I, p. 85). This history can contain typologies and genres, narrative classes, etc., various higher-order groupings which refer back to singular narratives as temporal totalities.

This topic is continued in the first chapter of TR II. Picking up again the guiding thread of the model, Ricoeur speaks of a "narrative intelligence," formed by and familiar with narratives, which "retains, integrates, and recapitulates its own history." The history of narrative has the character of a tradition:

\footnotetext{
...ce schématisme n'est pas intemporel. Il procede lui-même de la sedimentation d'une pratique qui a une hisțoire specifique. C'est cette sedimentation qui donne au schématisme le style historique que j'ai appele traditionalité...l'ordre qui peùt se dégager de cette auto-structuration de la tradition n'est ni historique ni anhistorique, mais transhistorique, en ce sens qu'il traverse l'histoire sur un mode cumulatif plutôt que simplement additif." (TR II, p. 27-28)
}

Ricoeur refers to Kant's schematism in the section on mimesis 2 , in the course of describing the transition from mimesis 2 to mimesis 3. The transition occurs in this manner: the schematization of individual works which are the "sediment" of the tradition cannot exist save through reading (TR I, p. 86, 105-10). Mimesis 2 is the locus of the "dynamic operation of configuration" (TR I, p. 102) which we are examining under the title of a syn. het. Mimesis 3 has to do with the after-effect of the narrative on the reader. Writer and reader can both be said to configure the work. This work of configuration, from the reader's point of view, leads to something more than a psychological or emotional effect, although it cannot be said to bring about an immediate alteration of maxims of conduct. In this regard, Ricoeur speaks of a 
fusion of horizons between the fictional world and the reader's world of experience. The difference underlines the importance of the end or the closure of a narrative: Ricoeur notes that a narrative can be a closed totality on the level of mimesis 2 , and at the same time remain open with respect to its possible effect upon a reader at the level of mimesis 3 (TR II, p. 36). The more convincing the ending, the greater the clarity of the effect upon later reflection (or in rereading). If the effect of a certain narrative, as individual or class, comes over time to be connected with a more general structure of expectation as regards narratives, then we could say that this effect has "sunk in" at the level of a pre-rational intelligibility, something which I understand without having to think about it, something more or less common to author and reader before the reception of the given text. That is the level of mimesis 1 , where we also find a general understanding of basic concepts such as agent, patient, circumstance, goals, means, action (including symbolic action; TR I, pp. 87-100).

Later references in TR II and TR III continue to underline the marks of totality, unity, singularity which belong to the plot as a temporal syn. het. The second chapter of TR II speaks of a "competition between the sequential dimension and the configurational dimension of the narrative--a competition which makes the narrative a successive totality or a total succession" (TR II, p. 75). The asymmetrically reciprocal relation between author and reader is further delineated: in the chapter on "games with time" (third ch. of TR II), Ricoeur describes the narrative as "the discourse of a narrator recounting the discourse of the characters" in the narrative (TR II, p. 132). Both author and reader are eventually seen as "figured" inside the narrative, the former figured in the narrative voice which "offers the text to be read", and the latter figured as the "virtual reader" at whom the narrative is aimed (TR III, p. 233).

This is not unconnected with the idea of the narrative as a totality. The reader is said to "apprehend the work intuitively as a unified totality", partly because he or she takes the text as someone's discourse, something produced by a person and not an effect of nature 
(TR III, p. 234-35). This "discourse" takes place under the suspension of disbelief, that enormous privilege or credibility granted to the author by the reader, who accepts, for example, the narrator's power to describe characters' thoughts. But although the granting of this privilege constitutes the door to the world of fiction, the reader is still obliged to reconfigure the work himself or herself:

\footnotetext{
Le temps du roman peut rompre avec le temps réel; c'est la loi mème de l'entré en fiction. Il ne peut pas ne pas le configurer selon de nouvelles normes d'organization temporelles qui soient encore perçues par le lecteur comme temporelles....(TR II, p. 43)
}

Ricoeur's discussion of the role of the narrator occasions another characterization of the narrative as a totality. Comparing "fictive time" and "historical time", he notes that the historian is obliged to maintain contact with the "time of the universe" which is computed according to the movement of the sun, i.e., chronology. For this reason, it's possible to think of different histories as each finding its place in one continuous and unique History--"like geographical maps laid end to end" (TR III, p. 185). Fiction has days and nights, but its events are not woven back into the time of the universe. When the narrator of a plot speaks of a historical event, the event "is no longer denoted, only mentioned":

\footnotetext{
...il faut dire que la Prémiere Guerre mondiale, en tant qu'événement historique, est chaque fois fictionnaliske de façon différente, ainsi que tous les personnages historiques inclus dans le roman. Ils gravitent desormais dans des spheres temporelles hétérogènes." (TR III, p. 187)
}

Once again, Kant gets called on to help specify the temporal heterogeneity or totality of these fictional spheres. Fictional narratives generate worlds of their own. Unlike histories laid end to end, which coalesce into History ( at least as written), fictional worlds are not " limitations of one unique imaginary world." In this respect, their temporality differs from time according to Kant, the parts of which exist only in so far as segments of one "unique successive time" are marked off. The temporal totalities produced by the syn.het./config.act are not 
"totalizable" (TR III, p. 185). Not totalizable, that is, in terms of each other; but there are a number of partial totalizations which go on within the sequence of operations from author to text to reader. There is a kind of totalization of the narrative sequence. This sequence may be complicated not only by anticipations or flashbacks, recurrent themes or symbols in a narrative. It is also possible, obviously, to present the temporal sequence of events in a way different from the sequence in which the ship descends the stream in Kant's second analogy of experience (B 232ff). ${ }^{4}$ The final episode in a work of fiction can be placed first--and yet we would not necessarily be entitled to assume that the author had sacrificed surprise for necessity in the sequence. The "end" would be figured otherwise, but would not disappear. Even a complete jumbling of the event-succession provokes an effort at reconstruction on the part of the reader, as long as he or she still takes the text to be a narrative.

This totalization is part of the work of reading. Without this work, no effect at the level of mimesis 3 . But the rearrangement of episodes, supposing that it is necessary, is only a special case of the reader's work. Within the narrative, the episodes are events linked to the point of view of a narrator, perhaps filtered through the point of view of one or more of the characters. By taking up or borrowing these points of view, concentric, telescoped, however partial or limited, the reader is able to figure the meaning of the events in the narrative, a meaning which imbues them with particular temporal qualities in fictive experience.

This work may be compared to the work which we perform when we try to represent to ourselves some sort of unity or continuity in the events of our own lives. In reading, we try to identify with a character, or with the narrative voice that offers the text to us. This unity in identification is the narrative identity which appears in the last chapter of TR III. This narrative identity, akin to ipseity (selfhood), can escape, Ricoeur says, from the paradoxes of personal identity which arise when I consider that I am different at every moment and yet possess an identity which extends over time as the same: 
L'ipstité peut échapper au dilemme du Même et de l'Autre, dans la mésure ou son identité repose sur une structure temporelle conforme au moddle d'identite dynamique issue de la composition poétique d'un texte narratif. Le soi-méme peut ainsi

- étre dit refiguré par l'application reflexive des configurations narratives. (IR III, p. 355)

As Ricoeur says in Soi, "the identity of the character is constructed in connection with the identity of the plot." (p. 168). The work of configuration which the reader performs in grasping the temporal totality of the narrative extends to the narrative identity of characters; this work is partly transferable onto the reader's own life. The notion of narrative identity, which rests upon a "summit" in TR (Soi, p. 32), is taken up again in Soi, again under the title of a syn. het. This is the model of connection, mentioned above, which allows succession in time and permanence in time to coexist with temporal discontinuity and instability. Such is the power of the discordant concord of the narrative.

But the constitution and transfer of narrative identity onto personal identity reaches a kind of limit, explored in Soi. The narrative theory of TR has to be worked over again: narrative only mediates between pre-understanding (mimesis 1) and self-understanding (the refigured self of mimesis 3 ) because the structure of narration itself points toward an ethics (Soi, p. 138-39). The concordance of plot and narrative identity cannot be reproduced in real life, for in many important ways I am not the author of my own life; though I try to grasp my life as a totality, I always fail; my life is materially bound up with the lives of others, such that it cannot be disentangled; finally, what ever justesse may belong to the end of a story, its characters do not owe their existence to hopes and projects which extend into the future, upon which real lives depend.

For all these reasons, the philosophy of the passivity of the self comes to limit the pretensions of narrative concordance, at the level of the plot or at the level of the cohesion of a life. 


\title{
II. The synthesis of the heterogeneous in The Critique of Pure Reason
}

Kant first refers to a syn. het. in a footnote added to the B edition, right after the categorical diagram of the titles of the principles of pure understanding (B 201-2). I am going to treat it, though, as if it had been appended to numbered paragraph 11, following the table of categories (B 109-13).

\begin{abstract}
All combination (conjunctio) is either composition (compositio) or connection (nexus). The former is the synthesis of the manifold where its constituents do not necessarily belong to each other. For example, the two triangles into which a square can be divided do not necessarily belong to one another. Such also is the synthesis of the homogeneous in everything which can be mathematically treated.... The second mode of combination (nexus) is the synthesis of the manifold so far as its constituents necessarily belong to one another, as, for example, the accident to some substance, or the effect to the cause. It is therefore synthesis of that which, though heterogeneous, is yet represented as combined a priori. This combination, as not being arbitrary and as concerning the connection of the existence of the manifold, I entitle dynamical. Such connection can itself, in turn, be divided into the physical connection of the appearances with one another, and their metaphysical connection in the a priori faculty of knowledge.
\end{abstract}

(The first part of the footnote suggests a reason Ricoeur did not mention Kant in this specific connection. Narrative composition comes entirely under the heading of nexus-connection; in other words, narrative composition isn't mathematical, but Kant's compositio is.) The footnote, duly relocated, makes sense as an extension of the discussion of the "nice points" suggested to Kant by the table of categories. There are four main categories or classes of categories: quantity, quality, relation, and modality. Under each of these titles there are three other titles which are also called categories, though by analogy with the table of judgments we might call them "moments" (B 95). Ricoeur shows his familiarity with this arrangement by speaking, for example, of the "first category of relation" (Soi, p. 359, n. 1). On the other hand Kant speaks 
often of the category of necessity, causality, etc., without referring to the title of the "class".

- The first "nice point" is the division of the main categories into mathematical (quantity, quality) and dynamical (relation, modality). The distinction is occasioned by the observation that only the categories of relation and modality "have correlates," i.e., their titles contain pairs of terms. (B 110) This difference "must have some ground in the nature of the understanding," Kant says. The footnote comes as near as any other of Kant's texts to supplying that ground.

In Kant, then, the syn. het. has to do with the dynamical categories of relation and modality. Now, based on the foregoing I will do something which is suggested but not guaranteed by it. If we take the footnote and apply it to TR, we can obtain the following: The plot of a narrative is a syn. het. Its parts do "necessarily belong to one another." The two examples Kant gives are just the first two in the series of categories of relation: if the relation of part to whole in a narrative seems to us not to be subsumable under the titles of the relation of substance and accident or of cause and effect, we can consider that nexus also refers to the relation of agent and patient. (The author is agent in giving the text, the reader passive in receiving it; but the author is passive with regard to the competence and expectations of the reader which exist at the level of mimesis 1 , to which he cannot ultimately be indifferent; while the reader is free to put whatever construction on a work it will bear--short of rewriting parts of it!)

The reader represents the elements of the narrative to himself or herself as combined a priori, based on conventions of fiction such as suspension of ordinary time, suspension of disbelief, etc. As for the connection of the existence of the manifold of story-elements, this can be compared to the actualization of the narrative in reading (although this already crosses, in a way, a category of relation with one of modality: actualization = actuality (Kant's single name for the category of existence/non-existence) plus a relation of cause and effect). 
The author, on the other side, can choose to allot one paragraph to a hundred years or seven hundred pages to a single day. The author thus arranges the fields of gravity that the narrative imagination must traverse, taking advantage of the privilege of fiction to enter the temporal depth of characters' thoughts. By adding to this a proportion of circumstance, surprise, and finality, the author creates a fictional world. If this procedure has any viability, it must be because the narrative is already a schema through which concepts of understanding, pure or derivative, are applied to appearances. Even though this is not taking place exactly as described in the Schematism, the narrative remains an appearance: in fact, it is twice act ( the "acte de l'intrigue" is performed twice, by author and wifr) and twice appearance (as material object and as representation/ imitation of action). It is a sort of "act-thing". 5 The categories are not here being applied to things in themselves, in violation of Kant's warning (B 185-87). Something happens (accidit) in the narrative, and yet its form is fixed. Both teleological and efficient causality are on display in it as it establishes a fictional world. As for metaphysical connection (the division in the footnote into physical and metaphysical connection follows the order of the categories; thus, the latter = assignment to a faculty of a priori knowledge), we have already touched on all three categories of modality. The possibility of entering the world of fiction involves the "suspension" of ordinary time, and we may surmise that the very status of reflection is involved in this act as well. The fictional world is actual for the reader, in the sense that he or she follows the twists of the plot with anticipation or recognition; for the author, the plot exists (or comes to exist) in a quite different way. The necessity which is intended, or which can be imagined between the elements of the narrative is a sine qua non of the narrative configuration as a transcendence of the succession of the text. Ricoeur refers the whole process, as we have seen, to reflective judgment and to the productive imagination (under the aegis of the pure understanding). If this syn. het. is not also referred to reason as the faculty of desire, it is perhaps because, as Ricoeur notes, reading narratives "exercises the imagination more than the will" (TR III, p. 358). 
The narrative is already a schema, a synthesis of the intuitive (reading involves an intuited succession) and the intelligible (of which narrative intelligibility is one type; cp. TR I, p. 106). This way of looking at narrative does not exceed the scope of the categories, as long as we can say that the narrative imagination alters time, but not to something else. The possibility of applying the categories and the schematism to the "thing" the narrative is, demands that there be a difference between the representation of what time is, as in the first analogy of experience, and the representation of temporal experience in the mimesis of action (B 224-27; cp. TR III, p. 68-89, and Soi, p. 143).

But doesn't Kant mean the syn. het. to be a matter of the dynamical categories alone? What about the characterization of the plot as a temporal totality? Totality, in the system of the first Critique, is a mathematical category, after all. The very fact that Ricoeur did not expressly indicate the relation between his use of the expression, syn. het., and Kant's, points to an adaptation rather than a transposition. But such an adaptation can be seen as developing something which Kant's idea contained potentially. The character of totality of the narrative work, with regard to the necessitation of the episodes seen as leading up to a certain conclusion, is the formal condition of the production of new perceived time-qualities. So the formal compatibility of narrative schematism and what we might call categorial analysis (on the basis of the system in the first Critique) requires that we look for a way to apply the syn. het. to the mathematical categories, even if only by analogy with the dynamical synthesis. Even if quantity and quality have to do with the synthesis of the homogeneous, it remains that neither is reducible to the other, and therefore a kind of syn. het. is required in order for them to be thought together in the same object. Before examining the role of the syn. het. in Kant's treatment of the antinomies of pure reason, we will look for something like that synthesis.

In fact, we don't even have to depart from the order of Kant's observations on the meaning of the categories prior to their deduction. The categories have to "accord" with the functions of judgment (B 111112). To this end, the table of judgments has in a way to be filled out 
with the "third moments" of singular and infinitive (judgments), which would not have constituted separate divisions "in a logic limited to the use of judgments in reference to each other." (B 97) Why would Kant affirm that the table of judgments is already transcendental in some respects (B 98), if the description of these functions was not relevant to the meaning of the categories, and if the "accord" between function and category shed no light upon the latter? The filling out of the table of judgments, in turn, is an index of the importance of the "third moments" in the table of categories. What is under discussion at this point (the next of the "nice points") is the meaning of the trichotomy of the categories. "The third category in each class always arises from the combination of the second category with the first." (B 110)

Thus..totality is just plurality considered as unity; limitation is simply reality combined with negation; community is the causality of substances reciprocally determining one anotlier; lastly, necessity is just the existence which is given through possibility itself. (B 111)

One point of interest in this declaration is that it anticipates the Schematism fairly exactly (and without mention of time ). Number, the "pure schema" (B 182) of quantity, "belongs to the category of totality" (B 111), that is the third category in the class of quantity. The mutual limitation of reality and (real) negation is continuity, the schema of quality (B 183). With regard to relation: Kant has alieady noted that a "special act of the understanding" is required for the combination of the first and second moments which produces the third. He repeats: one cannot, "by simply combining the concept of a cause and that of a substance, at once have understanding of influence, that is, how a substance can be the cause of something in another substance. Obviously in these cases, a separate act of the understanding is required..." (B 111) As for necessity, its expression in this instance is enigmatic, but Kant appears to be referring to the possibility of there being any possibilities: if anything whatsoever is possible, then something is necessary as its condition. One can see why Ricoeur complains that Kant only deals with the schematization of a time without a present, past, or future, a purely successive time (TR III, p. 89). The schemata of necessity on B 184 only repeat the categories of quantity, adding a time-mark to them. Kant's 
concern, in the Schematism, is to make sure the restriction which the schemata impose on the categories is observed. But this restriction is somehow related to the "special act of understanding" required for the synthesis of the third categories. If this act is thought away, it would seem that the four main titles of the categories vanish, along with the connection between the first and second, which gives rise to the third. What would remain are four pairs of concepts of reflection (B 317-18; B 325) which are precisely not combined. Some confirmation of this may be seen in Kant's declaration that the third categories are not simple derivatives from the other two.

If we could assume that there was a close connection between "what the schematism of understanding effects by means of the transcendental synthesis of imagination" (B 185) and the "special act of the understanding" involved in the thought of the categories, we might be led indeed to conclude that the schemata are not necessarily restricted to their role of restriction vis-à-vis the categories. But we cannot prove that the "new" time-qualities in narrative are derived from Time. Neither can we derive th "third moments" from concepts of reflection. Some sort of syn. het. is required.

The closest approach to a "narrative model" of this operation occurs with regard to quantity and quality, Kant does sketch the possibility of some such sort of exchange or entrecroisement. He does this when he reformulates the Scholastic proposition, quodlibet ens est unum, verum, bonum.

In all knowledge of an object there is unity of concept, which may be entitled qualitative unity, so far as we think by it only the unity in the combination of the manifold in our knowledge, as, for example, the unity of the theme in a play, a speech, or a story. Secondly, there is... the qualitative plurality of characters, which belong to a concept as to a common ground (but are not thought in it, as quantity). Thirdly, and lastly, there is perfection, which consists in this, that the plurality together leads back to the unity of the concept, and accords completely with this and with no other concept. This may be entitled the qualitative completeness (totality). ...these categories are here being transformed so as to yield 
connection of heterogeneous knowledge in one consciousness, by means of the quality of the knowledge as the principle of the connection." (B 114-15)

The Scholastic proposition omits the restriction of the categories, treating "criteria of thought" as "properties of things in themselves". (B 114) But Kant's reformulation of the proposition is only intended to show that these cross-categorie in not constitute additions to the table of categories. Something imp * sitt is half-concealed here: simple juxtaposition of categories can yield only derivative concepts. Is a syn. het. between originary concepts the key to original ones? With reference to narrative, though, we know already how to avoid hypostasizing the "text-in : iself", by interlacing the points of view of author and reader. The narrative, model of concordance, schematizes a plenary temporality as opposed to the open temporality of every day. In order to be perceived as such, this unity must be distributed (each character owes its presence in the narrative to its function in the plot). The concordance of this distribution is the operation of mimesis 2 . But the qualitative completeness of this knowledge is more the affair of the synthesis of the heterogeneous manifold by the reader, who operates the transition from mimesis 2 to mimesis 3 .

This interesting cross-category structure occurs at least twice more in the first Critique. In the first of these cases, Kant seems to be referring to the qualitative unity, not of a story, but of consciousness: this qualitative unity is said not to be the category of unity, but the "higher" combination (conjunctio = synthesis) which is "presupposed" by the category.(B 130-31) This combination or synthesis is said to contain the ground of "the possibility of the unierstanding". That phrase, here at the jumping-off place of the $\mathrm{B}$ deduction, refers to a theme which that deduction repeats at least five times. Intuitus originarius, intellectual intuition, intuitive understanding--all refer to the for-us unknowable synthesis of the "two stems" of human knowledge (B 29), sensibility and understanding. ${ }^{6}$ Our understanding, in determining sensibility, is originarius, acting spontaneously (von selbst). But our intuition is intuitus derivativus (B 72). If we could give ourselves a manifold of intuition, our intuition would no longer be temporal (B 159). It would no longer be 
sensible (B 149). Its representations would themselves confer existence upon their objects, generate their own objects (B 138-39; B145).This would be "An understanding in which through self-consciousness all the manifold would eo ipso be given..." (B 135). Our understanding, by contrast, "can only think..." (B 135).

This is why the categories have to be schematized, in order not to forget the distinction between an understanding which is applied to a manifold of intuition which comes to it "from elsewhere", and one which can apply to things-in-them-selves because it gives them to itself. But isn't our understanding that of a self? Is a thing-in-itself a self? Can it be? Isn't this limitation of the categories a kind of deduction-inreverse of the passivity of consciousness, especially with regard to that "empirical consciousness of my existence" which is only as certain as my consciousness of what is outside me? (Cp. B xl-xlii, end of Preface to 2nd ed.; also cp. B 274-279.) Isn't this the deduction of an understanding whose first action is a representation, whose first act is a response?

The largest role in argument which the syn. het. assumes in Kant occurs in the discussion of the solution of the dynamical antinomies (B $556 \mathrm{ff}$.) Briefly, the faculty of reason demands the unconditioned for the given conditioned. In the case of the mathematical antinomies, to ask to see or experience finite or infinite time or space or a simple substance is like asking someone to jump over his or her own shadow. Reason's "suit" is thereby dismissed in these cases. But since. the dynamical categories, with their correlates, already contain a syn. het., the unconditioned, which could not be presented in any series of sensible conditions, may be included as a "heterogeneous condition, not itself a part of the series..." (B 558-59). Thus Kant begins the determination of the "Possibility of Causality through Freedom" (B 506), which in virtue of its title can be reckoned to be another example of a crossing of categories, in this case modality and relation. 
The question in this section is whether or not the series of appearances, as a seamless web of natural necessity or efficient causality, can be doubled by an intelligible causality which is non-temporal and which does not itself appear (it is only indicated by a certain empirical sign), but which is the real cause of the appearances. If so, then freedom is possible, or in other words the causality of freedom is possible--and that possibility is all Kant seeks to preserve here.

By speaking of causality instead of causes and effects, Kant follows the line of the schema of causality as a rule-governed succession. (B 183) "Every efficient cause must have a character, that is, a law of its causality, without which it would not be a cause." (B 567) It is merely possible, then, that for a certain empirical character which binds together a series of appearances, there is an intelligible character which pertains to the same series as its cause. This intelligible character is a noumenon: "No action begins in the active being itself; but we may yet quite correctly say that the active being of itself begins its effects in the sensible world." (B 569) As noumenon, the intelligible character of a free causality can never be known, but only thought or attested by reason, "save in so far as the empirical serves for its sensible sign."(B 574)

But there are difficulties. Kant describes the empirical character of a person's actions as inferrable "through the powers and faculties which he reveals in his actions." (B 574) But the empirical character, sign of the intelligible, is itself already mediated by actions as signs which we interpret (that is, it is already intelligible in the ordinary sense). In another place, Kant says that the "appearances" which are taken as indications of the intelligible character (as a Denkungsart, mode of thought; B 579) "really yield an immediate knowledge only of the mode of sense, the empirical character" (mode of sense = Sinnesart). Further, the dynamical syn. het. which legitimated the entire "solution" to begin with is dismissed as "not applicable" to noumenal reason (B 581). Finally, Kant admits that "all we are justified in saying is that if reason can have causality in respect of appearances, it is a faculty through which the sensible condition of an empirical series of effects first begins." (B 
580) Now this possibility of reason having causality is described by Kant as "evident" when we consider the imperatives "which we impose as rules upon our active powers." (B 575) Reason "frames for itself with perfect spontaneity an order of its own according to ideas, to which it adapts the empirical conditions, and according to which it declares actions to be necessary, even though they have never taken place, and perhaps never will take place." (B 576)

It does seem as if this is a most unlikely place to look for new schemata based on an interpretation of the temporal syn. het. of dynamical categories. For even the syn. het. which might be thought to be possible in the entrecroisement of relation and modality could only seek to schematize time-qualities, time-relations, or time-modalities in different ways. But in Kant's solution, time has gone from being a nonoriginal intuition to being non-intelligible ( non-original $=$ sensible, = not intellectual, Ger. intellektuell: see n.3 to B 568; intelligible = intelligibel).

The general thesis of TR implies that the intelligibility of time lies in its being narrated. We saw briefly at the end of the first section how this intelligibility, reaching its highest expression in narrative identity, encountered a limit in certain unavoidable conditions which are constitutive of the self as such. For example, in configuration, I think the narrative, I encompass it, even if its mimetic self-containment makes this possible. But I do not so encompass my own life. It envelops me, and the distension which attends its dispersion in time and its uncertain borders with other lives can overwhelm me. Now, it is apparent that in construing freedom as non-temporal self-activity, Kant wishes to preserve freedom from any impurity in the form of an interest which would change freedom's quality and "lose" the notion he is trying to "save". But this point has been for a long time the center of Ricoeur's critique of Kant. In Kant, the roles of the pre-understanding of the ethical import of other selves, and of any gradual amelioration of moral character, are excluded from the formulation of the imperatives based solely on duty. As Ricoeur puts it, the categories of practical reason follow the model of the first Critique too closely. The principle of truth in the 
Transcendental Deduction is "radically monological" ( TR III, p. 327 ); the self, acting von selbst, is left outside its other. But perhaps the outline of a dialogical principle is after all possible based on a syn. het. of the dynamical categories which is not absolute.

I would like to propose, in response to these difficulties, an interpretation which only aims at suggesting undeveloped resources in the categorial system and the schematism--resources not developed by Kant, as Ricoeur has observed. I do this without prejudice to the analyses of these same topics in TR III and Soi, but again with an eye on the theme of the passivity of the self and of consciousness, as described in the latter work. ${ }^{7}$

The doctrine of the Unconditioned makes reason understandable and understanding unintelligible by projecting the notion of the absolute onto the dynamical categories. It is apparent in Kant's solution of the third antinomy that free causality is the affair of a kind of absolute self, one which may almost be said to be self-caused in its quality as free causality. It seems permissible to suggest that with regard to modality, the Unconditioned is the figure of absolute necessity; absolute existence corresponds to an intellectual intuition; absolute possibility describes the status of the ens extramundanum. As for relation, it is difficult to tell in the first Critique whether permanence (in time) is the schema of substance, or whether substance is the necessary representation of time itself as the abiding, the permanent in which all alteration takes place, but which cannot itself alter. (Cp. B 183, 225, 589; also IR III, pp. 68-85). Either way, though, absolute substance is that which is absolutely outside the absolute subject. Absolute causality is the intelligible character (or intellectual character) of freedom in Kant's account; under absolute community, I place the question of whether the distinction between this freedom and the necessary being (the ens extramundanum) can be maintained. That all these constructions are rather deconstructions of the category, is apparent from the fact that their correlates are all contradictions for reason: absolute contingence, absolute non-existence, absolute impossibility; absolute accidence, absolute effect, absolute combination of activity and passivity. 
Over against this impasse, it seems to me that the problems associated with the representation of free causality are rendered productive and give more to be thought if we relativize the "causality of the active being", and consider action as potentially unconditional. That way, we avoid the dichotomy between mechanism and the absolutely unconditioned. The series of appearances thus may be viewed, not only as a seamless web of natural causes (which it remains), but as a history, in which we seek to determine the identity of a self which is (in the words of Soi) intimately bound up with an other, whether this be another person, an other more-than-person, or oneself as someone else. ${ }^{8}$ This search looks forward in time for actions which are signs of maxims or principles of the self. The maxim, though, always has to be interpreted to be applied, and subsequent actions can modify the interpretation or formulation of the maxim, as would be the case if we were cast into doubt about our own principles and reviewed our actions as a result. The narrative identity of the self arises in the interplay between the self's self-forming intentions (the imagination of the self) and their expression in a history. The problem, then, is not how to grasp this identity, but how to limit that grasp, or its implied claim of selfknowledge.

The idea of unconditional action can arise when our principles are shaken--when in the cross-currents of our intentions we discover that an action which we had implicitly held to be unconditional was not. Suppose a friend wrongs me, and I decide at first to forget it. If afterward I go back on this decision and ask for an apology, the meaning of the entire sequence of events may be altered retroactively. The temporary merit or benefit procured by my forbearance may vanish, and in its place appears a grudge. Or suppose I interpret someone's action as unconditional; it is this interpretation which counts, and not the "absolute truth" of the action relative to the other person. Similarly, even if someone credits me with an unconditional act, I am obliged to reflect on the part of luck or chance in my having maintained my position. I can never know that I have accomplished an unconditional act; I can never make a promise that $I$ will be unable to abandon or break. It is impossible to ask for proof without remainder concerning 
such matters. In the dialectic of ipseity (selfhood) and alterity (otherness), all that is possible is an attestation of our selves and the character of our actions, and testimony regarding the actions of others. This attestation is made to others, before others, and to oneself as someone else, an attestation before the voice of my conscience.

In Soi, the notion of attestation defines the dialogical principle of truth, thence of which was visible in Kant. Attestation is an affirmation: the self as conditioned, and an affirmation of the condition under which unconditional action is possible. What is attested to in the hermeneutics of the self is my self as e lied, my presence to and with others, and my presence to myself, bicive the voice of my conscience, coming to me as if from someone else. This attestation is equally an injunction: the self which testifies is also what is at stake in its testimony. I will not try to deal any more fully with the hermeneutics of the self here. I will only indicate some ways in which it might be possible to link the dialectic of the ipseity of the self (as thinking, as spontaneous, as conscious) and the alterity of the self (as embodied, as with others, as having a conscience), with a syn. het. of modality and relation.

The $v:$ Jal relation of substance and accident is to be replaced by or remodeled according to the narrative relation of the temporal and the accidental. It is the thought of the tenses of time: what can happen (including what has happened), what is happening, what will happen? These are attestations of essential temporality, written into language. But the cross-category of a categorical imperatice which arises here (categorization is the ground of the first category of relation; imperative = necessity) does not encompass morality by its mere combined form. It only expresses the dialectical nature of the determination of identity and character across a series of actions and events. This modality of relation tends toward a kind of limit in the idea of eternity. In narrative, time itself can be said to "happen", that is, it can move faster or slower, or lose its measures altogether, etc. ${ }^{9}$ But eternity, as the Other of time, cannot "happen" except as the effect of the idea of eternity upon time, confronted with its other, sub specie aetemitatis. 
The modal relation of cause and effect adds the consideration of conditionality to that of causality. What could be the cause of X? What is the cause of $\mathrm{X}$ ? What is the (permanent) condition of X? I associate this dialogue with the imagination of causality. Just as the thought of time finds its limit in the tension between the ek-stases of time, or between them and their Other, so the thought of causality finds a limit, not just in the thought of the unconditional act which can never support a demonstration, but also in the thought of that which is presented to the self, but for which no conception of causality is ultimately sufficient. This limit is the idea of a creation from nothing, pure absolute spontaneity, original creation. An example: nature as a system. The imagination has a tendency to set itself up as an intellectual intuition, adapting empirical conditions to its ends, until it compares itself with the systematic totality of those conditions as the result of a creation from nothing. Another point which seems worth noting under this title is that no unconditional act can be considered as causal, whether with regard to myself or to another.

As for the modal relation of agent to patient, it includes the thought of the conditions of possibility of my belonging together with others, the thought of the actual condition of my relation to others, and the thought of the necessity of my belonging to others. The human race cannot be considered as the effect of any cause. But our predecessors and successors are conditions of the possibility of our belonging together; and the thought of the possible necessity of that belonging together, or its purpose, informs my search for unconditionality in my relationship with others and with myself. In effect, the concept of the person has to be maintained within a range between the thing and the thing-in-itself, in no way a thing.

Relative modalities: the possibility of my self, of my being a self, is related first of all to my embodiment, my having and being a body. This is the relative condition of the possibility of my being someone. That to which my existence is in the first instance relative is the existence of other persons. Finally, that in relation to which the self is necessary, in the sense of necessity which Ricoeur calls ontological engagement, is 
just attestation itself. There is no unconditioned necessity in existence; only the necessity of human beings to testify to their shared condition, and the being-enjoined of conscience before the unconditional voice of conscience.

\section{J.J. LEWIS}

\section{NOTES}

1. Paul Ricoeur, Temps et récit. 3 vols. (Paris: Seuil, 1983-85). Henceforth abbreviated as TR.

2. Cf. especially "Temps et récit" de Paul Ricoeur en débat (Paris: Editions du Cerf, 1990). Three essays in this bonk make mention of the syn. het.: a) Bobillot, J.P., "Le ver(s) dans le liuit trop mur de la lyrique et du récit," pp. 73-110; b) Grondin, Jean, "L'hermeneutique positive de Paul Ricoeur. Du temps au récit," pp. 121-38; c) Rochlitz, Rainer, "Proposition du sens et tradition: L'innovation semantique selon Paul Ricoeur," pp. 139-62. Also see the essay by Serge Meitinger, "Between 'plot' and 'metaphor'," Philosophy and Social Criticism 14 (1988), pp. 161-78.

3. Paul Ricoeur, Temps et récit, vol. 3, pp. 68-89; 349-92. Also see Paul Ricoeur, Soi-même comme un autre (Paris: Seuil, 1990); pp. 125-29, 131-33,141-43. Henceforth abbreviated as Soi.

4. Immanuel Kant. Critique of Pure Reason, trans. N. K. Smith (New York: St. Martin's, 1919). References to B edition pagination in the text.

5. For a similar mixed-structure notion, cf. the effet-signe described by Ricoeur in connection with la trace (TR III, p. 177ff.) The conjunction of effect and sign is one notion suggests that the effect-sign is constructed on the model of the intelligible character in the third antinomy. 
6. The idea of a syn. het. applied to the two roots generates the notions of intellectual intuition, intuitive understanding, etc., which Kant contrasts with human understanding.

7. Soi, pp. 367-410.

8. Ibid., p. 409.

9. Cf. TR II, pp. 113-20, p. 168ff.; also TR III, p. $191 \mathrm{ff}$. 